\title{
Las imágenes barrocas de Lacan
}

\section{The baroque images of Lacan}

DOI: $10.12957 /$ ek.2016.25052

\author{
Dr. Luciano Lutereau \\ llutereau@uces.edu.ar
}

Universidad de Buenos Aires - ARG

En la elaboración de la noción de mirada - que constituye un tópico esencial para el barroco, y en particular, para el barroco latinoamericano - Lacan promueve el análisis de la teoría comentando determinadas obras de arte. ¿Consiste este empeño en un recurso heurístico, metafórico, o en la asunción de un modelo programático? Para responder a este interrogante, elucidaremos un conjunto sistemático de obras de arte visual tematizadas por Lacan en el período comprendido entre los seminarios 8 y 11 de su enseñanza, período que delimita la introducción de la noción de objeto $a$.

PALABRAS-CLAVE Lacan. Barroco. Imágenes. Obras de Arte

In the development of the concept of gaze - which is an essential topic for the Baroque, in particular for the Latin America Baroque-, Lacan promotes the theory analysis commenting on certain works of art. Is this effort an heuristic, metaphorical, resource, or is the assumption of a program model? To answer this question we are elucidated a systematic set of works of visual art themed by Lacan in the period between 8 and 11 seminars teaching, period that marks the introduction of the notion of object $a$.

KEY-WORDS Lacan. Baroque. Images. Artwork 
El propósito de este artículo es iniciar un esclarecimiento sobre una pregunta metodológica respecto de la construcción de argumentos en psicoanálisis: en la elaboración de la noción de mirada, Lacan promueve el análisis de la teoría comentando determinadas obras de arte. Entonces, la pregunta epistemológica que se formula es la siguiente: ¿consiste este empeño en un recurso heurístico, metafórico, o en la asunción de un modelo programático? ¿Qué método subtiende este proceder?

Para responder a este interrogante, elucidaremos un conjunto sistemático de obras de arte visual tematizadas por Lacan en el período comprendido entre los seminarios 8 y 11 de su enseñanza, período que delimita la introducción de la noción de objeto $a$. La hipótesis que demostraremos se explicita en los siguientes términos: la relectura de lo imaginario, en el período circunscrito, con la introducción de la noción de objeto $a$, permite afirmar que esta noción se formaliza de acuerdo con un modelo extraído de una hermenéutica de imágenes barrocas.

De la exposición habrá de desprenderse, también, que la formalización de la mirada fue el modelo principal para la concepción del objeto $a$. Dicho de otro modo, si la mirada es el paradigma del objeto en psicoanálisis -según una célebre afirmación de Lacan-, esto se debe a que se expone como el hilo conductor de su elaboración teórica. Asimismo, no quiere decirse con esto que no haya razones clínicas en el viraje de la teoría del Lacan de los años en cuestión. En un párrafo anterior nos hemos referido a una "hermenéutica de las imágenes". Con esta expresión se indican dos cuestiones específicas: por un lado, en el período indicado Lacan elabora las obras visuales de acuerdo con referencias laterales a nociones de la tradición fenomenológica (provenientes de la fenomenología de Sartre, Heidegger y, fundamentalmente, Merleau-Ponty); por otro lado, la incidencia fenomenológica no se encuentra sólo en el comentario explícito de autores de esta tradición, sino en el recurso metodológico de considerar las obras de acuerdo con su modo de manifestación, en función de una aproximación descriptiva que busca elucidar estructuras formales e invariantes en su modo de aparición.

\section{Eros y Psique}

La clase del 12 de abril de 1961 del seminario 8 comienza del modo siguiente: "No porque en apariencia uno se distraiga de lo que es su preocupación central deja de encontrársela en la extrema periferia" (LACAN, 1960-61, 253). La clase es titulada "Psique y el complejo de Castración", dado que "la pequeña imagen... ilustra algo que hoy no puedo hacer mucho más que designar como 
el punto de confluencia de toda la dinámica instintual, cuyo registro les he enseñado a considerar como marcado por hechos del significante" (LACAN, 196061, 253), esto es, la castración.

Distintas afirmaciones del seminario permiten advertir que Lacan desarrolla su argumento realizando una lectura de la imagen. Por ejemplo, el hecho de que Psique no sea representada con alas es algo que llama la atención de Lacan dado que en el museo de los Uffizi ambos personajes son figurados alados (Cf. Lacan, 1960-61, 256). Recuerda, entonces, de acuerdo con una lectura iconográfica, que la representación con alas de mariposa suele ser un símbolo de la inmortalidad en la religión cristiana, y contrapone esta influencia al valor degradado que el motivo tendría en Zucchi debido a la versión de Apuleyo en la cual, según Lacan, el pintor se habría basado.

Lacan destaca que una primera lectura de la imagen podría resumirse en la representación de la amenaza de castración, lectura ayudada por la presencia de una espada en la mano de Psique; sin embargo, no deja de subrayar que esta dirección sería inadecuada. Lacan no lee la imagen en su significado manifiesto, sino en su composición, en las leyes por las cuales se organiza:

Advertirán ustedes lo que se proyecta aquí significativamente como una flor, el ramo del que ésta forma parte y el florero donde se inserta. Verán ustedes que, de una forma muy intensa, muy marcada, esta flor es propiamente hablando el centro mental visual del cuadro. (LACAN, 1960-61, 254)

El florero se presenta, de acuerdo con la utilización de las luces y sombras, de modo destacado, especialmente oscuro, si se lo acompaña con la luminosidad del cuerpo de Eros: "Esto se ve en el estilo mismo del cuadro, destacado de tal forma que no se trata en absoluto, lo que les digo, de una interpretación analítica." (LACAN, 1960-61, 255)

Lacan no está realizando un psicoanálisis de la obra de arte; muy por el contrario, está tomando de la composición lumínica de la obra una estructura formal que, luego, utilizaría para articular la relación entre el falo y la imagen, entre el vacío y su representación. Debería anticiparse que este esquema formal describe, en pocas palabras, la función de la falta en el campo escópico. Sin más dilaciones, a partir de este momento ya hemos comenzado a demostrar que las obras visuales de las que Lacan se sirvió en el desarrollo de su enseñanza ocupan un lugar argumental y no sólo persuasivo o de ilustración. 
La representación sugestiva del vacío es una característica formal propia del manierismo. En la pintura de Zucchi, la intensidad del florero es sopesada con el punto lumínico de la lámpara indicado en una línea descendente, llamando la atención sobre los pliegues del cortinado en que transcurre la escena. Esta tendencia de la representación a ofrecerse en "bambalinas" es un rasgo manierista que ofrece el marco para escenas recargadas y variopintas: un friso, un arco, un perro, etc., son distintos elementos que proliferan en torno a este vacío generador, condición de posibilidad de la metonimia que desplaza su ausencia. Es precisamente de la condición del falo en tanto signo de lo que intenta dar cuenta Lacan al recurrir a Zucchi. En su articulación pone de manifiesto la estructura del velo:

La función del velo se revela como el soporte de las imágenes que capturan el deseo y cuyo valor de seducción radica en su capacidad para cubrir la falta. Al revelarse la complicidad entre el objeto y la nada, se descubre la articulación de lo simbólico y lo imaginario. En este estadio el espejo se convierte en un velo, y merced a esta operación, lo visible se anuda a lo invisible. (RECALCATI, 2006, 116)

En un apartado siguiente habremos de volver a la relación entre lo visible y lo invisible. La estructura de la imagen de Eros y Psique pone de manifiesto la fugacidad del deseo, su forma metonímica. Lacan se refiere en esta clase al complejo de castración como una paradoja cuya consistencia estriba en manifestar su carácter diferencial respecto de los otros objetos que venía elaborando en el seminario: el oral y el anal. La paradoja del complejo de castración se manifiesta, para Lacan, en esta manifestación mediatizada por una ausencia:

De modo que, de lo que se trata -y está concentrado en esta imagen- es ciertamente del centro de la paradoja del complejo de Castración. Es que el deseo del Otro, en tanto es abordado en la fase genital, de hecho nunca puede ser aceptado en lo que llamaré su ritmo, que es al mismo tiempo su huir. (LACAN, 1960-61, 263)

El falo es ese elemento enigmático, supuesto, que posibilita con su veladura la proliferación manierista de los objetos que pueden encarnar su referencia negativa: "Si el sujeto entra en posesión de la pluralidad de los objetos que 
caracterizan al mundo humano, lo hace en la proporción de cierta renuncia al falo." (LACAN, 1960-61, 266)

A partir de su ausencia, cualquier cosa puede ser un signo del falo. Cabe destacar que, en este momento de la enseñanza de Lacan, la conceptualización del objeto del deseo aún se realizaba de acuerdo con un esquema intencional, tal como lo demuestra la formulación del objeto agalmático, ese objeto de interés privilegiado -objeto de la demanda, aunque esquivo de la misma- "del que no se puede decir qué es" (LACAN, 1960-61, 250). Asimismo, este objeto es entrevisto como complemento fantasmático; y el problema de la castración, centro de la economía del deseo, se resume, respecto del Otro, en una pregunta: “¿Cómo es que puede y debe convertirse en algo exactamente análogo a lo que se puede encontrar en el objeto más inerte, o sea, el objeto del deseo, $a$ ?" (LACAN, 1960-61, 265). El objeto $a$, en tanto partenaire del fantasma, debe ser distinguido de lo que luego desarrollaremos como objeto causa, resto caído en la operación de estructuración del sujeto por el encuentro con el Otro.

Junto a la conceptualización del falo como signo negativizado (-phi), también se presenta en el seminario 8 otra versión del signo fálico: "Un signo representa algo para alguien y, a falta de saber qué representa el signo, el sujeto, ante esta pregunta, cuando aparece el deseo sexual, pierde al alguien a quien el deseo se dirige, es decir, él mismo." (LACAN, 1960-61, 249)

En este punto, el falo encuentra su dimensión de símbolo. Los efectos de esta presentificación simbólica del falo son los que se hacen sentir en la lectura de otra imagen: El bibliotecario de Arcimboldo. A este motivo nos dedicaremos en el apartado siguiente.

\section{El bibliotecario}

En el seminario 8, luego de decir que la composición extremadamente minuciosa de los cuadros manieristas hace sensible lo que, en su momento, se conoció como análisis estructural, Lacan avanza en la hipótesis de que, en el cuadro de Eros y Psique, el pintor de las flores no haya sido Zucchi sino algún primo o hermano, dado que la técnica de su estilo llevó a que ciertos críticos lo relacionaran con otro pintor sobre el cual quiere llamar la atención: Arcimboldo. La clase es del 19 de abril de 1961, y su tema principal, articulado con la siguiente clase del seminario, está en dar cuenta de las respuestas a la manifestación del falo simbólico.

En su obra sobre el bibliotecario de Rodolfo II, Arcimboldo representa a este 
personaje "mediante un montaje ilustrado hecho con los utensilios fundamentales de la función del bibliotecario - o sea, libros- dispuestos en el cuadro de tal forma que la imagen de un rostro, más que quedar sugerida, verdaderamente se imponga" (LACAN, 1960-61, 251). La particularidad de la composición de este retrato satírico se encuentra en la disposición de los libros, algunos de frente, pero otros en escorzo. Lacan intuye que esta disposición tiene cierta relevancia, lo cual encuentra manifiesto en el efecto de imposición del rostro que la imagen promueve, antes que en atribuirle cierta función evocativa. Lo curioso de la presentación escorzada de algunos de los lomos y de las hojas de los libros está en que sugieren las partes del rostro que se presenta, es decir, Arcimboldo se propone neutralizar la referencia evocativa y, al mismo tiempo, la incorpora. El bibliotecario es una especie de caligrama. A diferencia del efecto anamórfico, que expondremos más adelante, en esta obra la dualidad queda expuesta, y en fuga, a cada momento, con tomar tan sólo cualquier perfil de los elementos compositivos de la imagen. El manto plegado recogido en el fondo de la tela avanza de modo sugerente, alternando entre la capa del bibliotecario y un cortinado que reestructura la escena: si es vista como una capa la tensión se reparte hacia la derecha abriendo un campo de oscuridad desvelado e inadvertido en dicha representación; si la figura es descompuesta, el equilibrio es sopesado hacia la izquierda y el cuadro se desestabiliza.

A partir de la articulación de los elementos compositivos, su forma vaciada tiende hacia el conjunto visual, y la imagen comienza a funcionar comos si fuera un jeroglífico. De este modo, El bibliotecario exige vaciar sus elementos de cualquier remisión a un significado para que pueda verse el rostro; $\mathrm{y}$, al mismo tiempo, presentifica este rostro de un modo que no es evocativo. Es otra función que la de la significación la que Lacan destaca en esta pintura:

Este procedimiento manierista consiste en realizar la imagen humana en su figura esencial mediante la coalescencia, la combinación, la acumulación de un montón de objetos, cuyo total [debe leerse aquí el falo simbólico] estará encargado de representar lo que en consecuencia se manifiesta a la vez como sustancia y como ilusión. (LACAN, 1960-61, 272)

El falo simbólico es ese elemento de la estructura que, subtendido, articula el campo significante y desplaza la falta en la imagen. Su presencia velada ya ha sido estudiada en un apartado anterior. A su vez, en tanto significante, el falo es 
el elemento de la estructura que vacía de sentido a los signos para introducirlos en el orden del significante. ${ }^{1}$ Sin embargo, en esta clase, Lacan avanza un paso más al formular que el falo más que un significante es un símbolo. Por esto la noción de símbolo puede ser usada en un sentido específico que puede prestarse a confusión: el falo como símbolo presupone el orden del significante. En el cuadro de Arcimboldo se hace notable este orden siempre que su estructura íntima pone de relieve el rostro al neutralizar el sentido de sus elementos. Debería llamarse a este rostro una inscripción alegórica antes que una representación, dado que a partir de ahora el objeto es totalmente incapaz de irradiar un significado. La función simbólica que toma el falo en esta clase del seminario 8 es la de convertirse en una presencia real: "Al mismo tiempo que la apariencia de la imagen se sostiene, se sugiere algo que se imagina en el desensamblaje de los objetos." (LACAN, 1960-61, 272)

Lacan advierte respecto de que la relación entre el significante fálico y la cadena significante es una relación de o bien ... o bien ..., dando cuenta, de este modo, de cuál sería el efecto de la aparición del falo en otro lugar que su veladura: "Dejar surgir el falo en su presencia real, ¿no es como para detener toda la remisión que tiene lugar en la cadena de signos y, más todavía, para hacer que los signos vuelvan a no sé qué sombra de la nada?" (LACAN, 1960-61, 279)

La presencia no velada del falo en la presencia real se explicita como aquello que puede aparecer en los intervalos de lo que es protegido por el significante. La promoción de Lacan de la función del intervalo es para "situar esta presencia real en alguna parte -y en un registro distinto del de lo imaginario" (LACAN, 1960-61, 296). El entre-dos del significante no se confunde con la metonimia de la imagen. Tal como lo muestra la pintura de Arcimboldo, un cambio en la distribución de la mirada y en la interpretación del pliegue colgante detrás de la acumulación de libros modificaría la posición izquierda del cuadro revelando una falta de soporte por la cual se caería toda la pila y, con ella, el rostro figurado.

La existencia de un significante de la falta no quiere decir que haya un significante que falte. Que haya un significante excluido del significante no implica que ese significante velado pueda ser repuesto en la forma del significante. El referente del falo simbólico es la presencia real del deseo como un intervalo antes que como un vacío. El vacío es la imaginarización de una falta. El vacío sólo puede anoticiarse por la presencia simbólica de lo que está ausente. La

1 "Este significante está siempre escondido, siempre velado. Hasta tal punto, por Dios, que les produce asombro, destacan como una particularidad y casi una acción exorbitante que se vea su forma en algún rincón de la representación o del arte. Es más que infrecuente, aunque por supuesto ocurre, verlo intervenir en una cadena jeroglífica" (LACAN, 1960-61, 278). 
presencia real del falo simbólico nombra otra estructura formal que la del par presencia-ausencia y este referente sólo es formalizable de acuerdo con una topología de superficies y agujeros. No obstante, es oportuno restituir, aunque en un esbozo, que un antecedente de esta topología puede encontrarse en la influencia topológica del pensamiento heideggeriano: en el anonadamiento de la significatividad (Bedeutsamkeit) del mundo, según la célebre descripción de Ser y Tiempo, la aparición "ante los ojos" del objeto supone la alteración de la estructura de remisiones en que el útil se da a la mano. Del mismo modo, el falo simbólico como presencia es la puerta de entrada a una topología de cercanías ${ }^{2}$ y alejamientos, a partir de la introducción del objeto $a$, cuya fenomenología es uno de los temas de Lacan en el seminario 10:

Representar algo para alguien, eso es precisamente lo que hay que romper. Porque el signo que hay que dar es el signo de la falta de significante. Es, como ustedes saben, el único signo que no se soporta, porque es el que provoca la más indecible angustia. (LACAN, 1960-61, 267)

El significante de la falta de significante, el falo simbólico, remite con su aparición a la suspensión de la remisión significante de los signos. Esta particular encrucijada es reconducida por Lacan al fenómeno de la angustia, fenómeno que en su estructura requiere la introducción de la noción de objeto a en el seminario 10.

\section{Santa Lucía y Santa Ágata}

El seminario 10 se propone como una reconstrucción de la condición de posibilidad del deseo. El modelo del deseo hasta entonces estaba en el motivo fenomenológico de la intencionalidad, por el cual el deseo declinaba hacia el amor fascinado en la forma del objeto agalmático. A partir de este seminario el deseo sería reconstruido en su relación con el goce y con la angustia como pasaje estructural. Esta reconstrucción encontraría una elucidación posterior de su constitución en las dos operaciones de causación del sujeto en el seminario 11,

2 "Cuando en el cuidado el existente se trae algo a su cercanía, esto no significa un fijar algo a un lugar del espacio que esté a la menor distancia... 'en la cercanía' significa: en el círculo de lo inmediatamente a la mano avistado. El acercamiento no se orienta por la cosa" (Heidegger, 1927, parágrafo 23 ). 
alienación y separación, que aquí no podremos más que mencionar, retomadas de modo sistemático por Lacan en el escrito "Posición del inconsciente" (1964).

La estructura cuenta con un agujero. El objeto $a$ es ese agujero que porta la estructura. Se plantea entonces la tarea de articular la relación entre el agujero y la falta. El velo, en tanto operación simbólica sobre la imagen, indica una falta cuya característica es la metonimia; en cambio, el agujero es un objeto de lo real. La relación entre ambos se establece diciendo que la imagen negativizada recubre el agujero de la estructura haciendo de éste un vacío. El recubrimiento simbólico del agujero es lo que hace de éste ese vacío generador que es el deseo. De este modo, la estructura es formalizable en dos niveles: el deseo y el goce, el vacío y el agujero. La introducción del objeto $a$ es un "más acá" del deseo en la enseñanza de Lacan, sostenido en el propósito de dar cuenta de su causación.

Para avanzar en este derrotero, y en la búsqueda de otras estructuras formales (además del vacío y la función del velo) consideramos que las dos pinturas de Zurbarán que Lacan retomó en el seminario 10-Santa Lucía y Santa Ágata- deben ser analizadas a un mismo tiempo. Si las considerásemos por separado, de Santa Lucía podría destacarse, para el caso, la particular forma de su pelo recogido, o la pluma que parece llevar en la mano escondida y que asoma desde detrás.

Por otra parte, en Santa Ágata podría llamarse la atención sobre su collar perlado, la austeridad y la dignidad de su mirada, la simplicidad de su figuración. Sin embargo, por esta vía, desplegando el catálogo metonímico de las formas iconográficas no avanzaríamos demasiado en el análisis que las convoca a esta altura de la enseñanza lacaniana. No se haría más que restituir la función agalmática que Lacan busca superar en este momento de su seminario. En este punto, quisiéramos poner el énfasis sobre el hecho de que Lacan no hace un análisis exhaustivo de la composición de estas obras. La propuesta implícita radica, entonces, en que no puede dejar de advertirse que ambas figuras tienen una composición semejante salvo en la inversión simétrica de la posición, esto es, puede pensárselas enfrentadas, una a otra, como si de una imagen y su reflejo se tratara. Entonces, junto a los caracteres pictóricos que distinguen una obra de la otra, cabría subrayar el papel de la orientación en ambas, encontrando en esta característica un factor importante a tener en cuenta si recordamos que, en este seminario, Lacan realiza una nueva lectura del estadio del espejo. En vez de dejarnos atrapar por el rasgo anecdótico que muestra a ambas mujeres con fragmentos de sus cuerpos en sendas bandejas, consideramos que en la elección de Lacan de tratarlas al mismo tiempo hay una razón estructural: 
Lo que en las imágenes de Lucía y Ágata puede interesar verdaderamente, la clave está en la angustia. [...] Las personas encantadoras que nos trae Zurbarán, presentándonos esos objetos en un plato, no nos presentan sino aquello que en este caso puede constituir $-\mathrm{y}$ no nos privamos de ello- el objeto de nuestro deseo. Estas imágenes no nos introducen de ningún modo, en lo que a la mayoría de nosotros se refiere, en el orden de la angustia. (LACAN, 1962-63, 177)

El aspecto principal destacado por Lacan en estas pinturas es lo que no puede ser visto y, en este punto, constituye un antecedente de los planteos sobre lo invisible en el seminario 11. El espacio imaginario y especularizable es el que tiene la propiedad de ser orientable; en cambio, la condición del objeto $a$ conlleva una concepción del espacio de otro orden: una topología, que ya había comenzado a formalizarse en el seminario 9 sobre el modelo del toro -según ya hemos explicado-, y que en este seminario encuentra un desarrollo complementario en la banda de Moebius y el Cross-cap. "Cuando les hablé de los senos y de los ojos a partir de Zurbarán, de Lucía y de Ágata, ¿no les llamó la atención que estos objetos $a$ se presentarán ahí bajo una forma positiva?" (LACAN, 1962-63, 191)

La forma positiva de presentación del objeto $a$ no debe confundirse con la presentación de las formas del objeto $a$, sus encarnaciones, en esos objetos separables que son la mirada, las heces, el seno, la voz y el falo. Como hemos dicho anteriormente, el objeto $a$ es un agujero en la estructura, siendo que estas formas anatómicas son partes privilegiadas del cuerpo que pueden enseñar la particularidad de una lógica del agujero y su vaciamiento a partir de una operación simbólica. De todos modos, es significativo que en este seminario Lacan recurra, después de años de enseñanza alrededor de la lógica del significante, a metáforas biológicas y a operaciones reales de separación. En particular, la circunscripción de la castración a partir de la detumescencia del falo como órgano es una dirección extraordinaria en su enseñanza. No es que en otras ocasiones Lacan no haya realizado la ecuación entre el falo y su encarnación orgánica, ese privilegio es destacado en los seminarios anteriores, sino que en este seminario Lacan no hace del falo otra cosa que su encarnación genital. De este modo, la castración se vuelve una operación más dentro de un conjunto de separaciones englobado bajo la propiedad del corte. No profundizaremos esta línea en este contexto, pero sí destacaremos que el corte es una operación topológica que formaliza definitivamente la enseñanza de Lacan en un modelo topológico. 
La clase del 28 de noviembre de 1962 comienza una nueva lectura del estadio del espejo. Si bien el esquema completo reproduce la articulación de la “Observación sobre el informe", la versión simplificada del mismo hace participar la relación entre el objeto $a$ y la función fálica. Dicha relación es formulada por Lacan del modo siguiente: "El investimiento de la imagen especular es un tiempo fundamental de la relación imaginaria. Es fundamental en la medida en que tiene un límite. No todo el investimiento libidinal pasa por la imagen especular. Hay un resto.” (LACAN, 1962-63, 49).

De este modo, Lacan coloca del lado del sujeto, en la imagen real, el objeto $a$, y en la reflexión especular, en el campo del Otro, la inscripción imaginaria de la falta en la imagen virtual. Esta formulación en términos libidinales ya se presentía en la última parte del seminario 8 , siendo que su formalización más acabada se encontraría, posteriormente, en el mito de la laminilla del seminario 11 y en el escrito "Posición del inconsciente". La función del resto, como la contraparte de la falta, es una herramienta que también es sensible en el esquema de la división subjetiva de este seminario 10. Toda división cuenta con un resto inasimilable. Es curioso que Lacan, en esta clase del 28 de noviembre, reniegue de la postura que quisiera ver en su enseñanza dos momentos. Podría pensarse que la razón obedece a un motivo en la construcción de la teoría. La explicitación de un pliegue profundo, la elucidación de las condiciones de posibilidad de una estructura, no plantean una ruptura con lo establecido en un primer momento. Si bien puede decirse que Lacan no razona siguiendo un esquema lógico-formal de argumentos encadenados en premisas y conclusiones, deductivamente relacionados, esto no quiere decir que no formalice su enseñanza con argumentos. El establecimiento de condiciones de posibilidad, propio de los argumentos trascendentales -reconocibles en Kant así como en varios autores de la tradición fenomenológica- es suelo firme del desarrollo lacaniano.

A partir de la introducción del objeto $a$, la noción metonímica de objeto, caracterizada desde un punto de vista intencional, es reapropiada en su condición de producción, y envuelta, por la teoría del corte y del agujero en lo real. La introducción del objeto $a$ representa la apertura al "piso inferior" de la teoría que permite volver a causar la teoría de la falta y su inscripción imaginaria. A la teoría del falo, en un piso, corresponde la explicitación de la teoría del objeto $a$, como un "piso inferior". Dada esta especificación, cabe retomar su exposición en el contexto de la obra de arte visual.

En el campo visual, el objeto $a$ no aparece en tanto visible. La presencia del objeto a se manifiesta, pero no aparece objetivamente. El seminario 10 describe una fenomenología de la proximidad del objeto $a$, pero no su aparición; 
reconstruye su presencia, pero no por eso lo da a ver. Es interesante advertir el carácter espacial de varias declinaciones de Lacan, por ejemplo, el objeto al que se apunta, o que está delante. Al mismo tiempo, ese espacio tiene, a veces, la forma de lo visual. Así, por ejemplo, el estadio del espejo es la matriz a la que Lacan retorna para articular una de las principales características del objeto $a$ : no ser especularizable, esto es, no puede aparecer en el espacio del espejo. En el campo especular, de este objeto, sólo podemos admitir una cicatriz o sutura.

\section{El sacrificio de Isaac}

La clase del 20 de noviembre de 1963, clase impar del seminario Los Nombres del Padre, representa el punto de culminación, de máxima consecuencia de la introducción de la teoría del objeto $a$-en el período aquí circunscrito-. No nos detendremos, en este punto, en una reconstrucción de la teoría del Nombre del Padre en Lacan, dado que nuestro interés está en extraer las consecuencias metodológicas de este pasaje.

J.-A. Miller ha destacado que el seminario de Los Nombres del padre concluye una serie que se ordena desde el seminario 9 y se consolida en el seminario 10. El seminario de Los Nombres del Padre representaría, entonces, la conclusión del trabajo de estos dos seminarios, uno dedicado al tema de lo Uno, y el otro al tema del Otro, a aquello que hace que el Otro no sea reducible al Uno, esto es, el objeto $a$.

\footnotetext{
¿Y qué viene a ser ese nombre del Padre en más, en plus? El nombre del Padre no designa nada más que el poder de la palabra. De tal manera que los Nombres del Padre, que se pueden buscar, son todos mitos de la pérdida de goce. (MILLER, 1992, 41)
}

Se entiende, entonces, la relación de necesidad que queda establecida en el pasaje del seminario 10 a este Seminario: si aquél había concluido con la fenomenología de las pérdidas de goce, en las distintas formas del objeto $a$, "no sin motivo" (LACAN, 1962-63, 364) Lacan anticipa un seminario que trataría sobre la relación entre las huellas del goce, marcas vacías del cuerpo, y el velo que las recubre. 
Miller reconstruye metodológicamente el curso de estos seminarios como el pasaje de los nombres a los matemas: "Lacan se propone hacer pasar el psicoanálisis del respeto religioso hacia las fórmulas de Freud, las expresiones de Freud, los conceptos formulados por Freud, hacia un uso científico del concepto.” (Miller, 1992, 18)

Testimonia de este recorrido el título mismo del seminario 11: Los 4 conceptos fundamentales del psicoanálisis. Los nombres de Freud -inconsciente, repetición, transferencia y pulsión- son tomados en el seminario con el propósito de hacerlos pasar a la perspectiva del concepto. Sin embargo, en el comienzo del seminario 12 Lacan daría por fallido este intento. ${ }^{3}$ Los conceptos no se sostienen, la noción de repetición se desdibuja en tyché y automatón, el inconsciente se superpone al automatón de la repetición, la transferencia, al mismo tiempo, pone en acto la pulsión, etc.

En este punto, es preciso volver al campo de las imágenes ¿Por qué Lacan toma una pintura de Caravaggio en el seminario que anticipa la barradura de los nombres de Freud? Este camino ya se dejaba entrever en el seminario 10 cuando proponía ir "más allá del complejo de castración", del extravío que representaría la roca dura freudiana. La lectura lacaniana del deseo de Freud comienza, a partir de este seminario, un movimiento que es, a su vez, un más allá de Freud. Entonces, ¿qué es lo que permanece invisible en El sacrificio de Isaac? Puede decirse, inicialmente, aunque de un modo algo críptico, que de lo que se trata, en El sacrificio de Isaac, es, nada menos, que del "sacrificio de Abraham", esto es, del Padre: "Hay un hijo, la cabeza apretada contra el pequeño altar de piedra, ese niño hace una mueca de sufrimiento, el cuchillo de Abraham se levanta sobre él, el ángel que está allí es la presencia de aquél cuyo nombre no es pronunciable."

En esta oportunidad, Lacan realiza un comentario minucioso de la obra. $\mathrm{Su}$ método de lectura de la imagen comprende dos estrategias relacionadas: por un lado, interroga a la imagen de acuerdo con sus elementos ideográficos, re-

3 "Ya ven por qué vía me decidí a introducir este año, buscando darles su tono, lo que yo llamo Problemas cruciales para el psicoanálisis. El año pasado hablé de los fundamentos del psicoanálisis. Hablé de los conceptos que me parecen esenciales para estructurar su experiencia y pudieron ver que en ninguno de esos niveles se trató de verdaderos conceptos; que no pude hacer que ninguno resistiera, en la medida en que los hice rigurosos, en el lugar de referente alguno; que siempre, de algún modo el sujeto, que es quien aporta esos conceptos, está implicado en su discurso mismo; que no puedo hablar de la apertura o del cierre del inconsciente sin estar implicado, en mi discurso mismo, por esta apertura o este cierre; que no puedo hablar del reencuentro como constituyente, por su misma falta, del principio de la repetición, sin tornar inaprensible el punto mismo donde se califica esta repetición". Clase 2 de diciembre 1964. 
poniendo al detalle la historia de Abraham en la tradición y el simbolismo de algunos de los elementos figurativos. ${ }^{4}$ Sin embargo, "esto no es todo lo que puede verse sobre la estampa de Espinal, hay todavía más cosas a derecha e izquierda en el cuadro de Caravaggio, la cabeza de cordero que introduzco bajo la forma del shofar."

El sacrificio de Isaac es una pintura que podría caracterizarse por dos rasgos sobresalientes: el uso enfático de la luz, en un claroscuro organizado desde un foco lumínico exterior a los personajes, y la gestualidad de estos personajes, en especial el instante detenido se conserva paradigmáticamente en el rostro de Isaac. Los colores son atenuados para esta obra, en comparación con la producción anterior del artista. Este no deja de ser un rasgo significativo, si consideramos la mención que realiza Lacan: ¿en qué consiste la alusión al shofar, subrayando la presencia del carnero? Pareciera que Lacan busca en la imagen algo más que una presencia visual. Consideramos que no es un detalle menor que Lacan utilizara la segunda versión del sacrificio que hiciera Caravaggio, es decir, la de 1603, siendo que hay una primera versión del mismo tema, fechada en 1596. Esta primera versión se caracteriza por una profunda oscuridad y una luz lateral que embiste a los personajes desde detrás, la orientación de la pintura es inversa, la túnica de Abraham recarga los pliegues intensos de un rojo intenso. La cara de Isaac permanece impávida, como escrutando celosamente la conversación de su padre y el ángel, casi en el pedido de que la historia continúe. Es notable, en este punto, la diferencia entre una pintura y su doble: Lacan eligió una pintura que aún acontece en el tiempo, que repone en la boca abierta de Isaac la contorsión de los músculos. Es el instante del temblor lo que llama su atención en esta pintura de Caravaggio y lo que hay que investigar para entender lo que permanece velado en la alusión al shofar.

En el seminario 10 Lacan ya había presentado la función de la voz en tanto "lo que ocurre cuando el significante no está únicamente articulado... sino que es emitido y vocalizado" (LACAN, 1962-63, 270). Al mismo tiempo, ponía sobre aviso de no confundir este plano con el de la fonemización, dado que este campo se encuentra regido por oposiciones. Es en este punto que Lacan presen-

4 "Este ángel retiene el brazo de Abraham, y sin el consentimiento del padre Teilhard, sea lo que sea este ángel, es a título de El Sadday que está allí. Siempre visto tradicionalmente allí. Es sin duda a título de esto que se desarrolla todo lo patético del drama al que nos arrastra Kierkegaard. Antes de este gesto que lo retiene, Abraham llegó ahí para algo, Dios le dio un hijo y le dio la orden de traer al pequeño para una misteriosa cita, atado de pies y manos como un cordero, para sacrificarlo. Antes de conmovernos, podríamos recordar que, hacer el sacrificio de un pequeño hijo al Elohim era algo corriente en aquella época. Esto ha continuando hasta tan tardíamente que fue necesario, para que esto cesara, que el ángel y los profetas detuvieran a los israelitas para que no volviesen a hacerlo". 
ta al shofar también remitiendo a las campanas del Nô japonés, y otros objetos resonantes, siendo que lo que busca poner al descubierto es una "función muy particular, de precipitación y de ligazón" (LACAN, 1962-63, 270). Luego de presentar la condición de separabilidad del objeto voz, Lacan formula que "para orientarnos, tenemos que situar lo nuevo que introduje respecto al piso articulado anteriormente, que concernía a la función del ojo en la estructura del deseo" (LACAN, 1962-63, 272). De este modo, el análisis que se busque realizar del Sacrificio de Isaac debe poner en relación la mirada y el objeto voz, como si de dos pisos se tratara, teniendo en cuenta que: “...todo lo que se revela en la nueva dimensión parece estar enmascarado en el piso anterior, al que necesitamos volver un instante para que resalte más lo nuevo que aporta el nivel donde surge la forma de la llamada voz." (LACAN, 1962-63, 272)

Quiere decir esto, entonces, que hay un índice del funcionamiento de la voz que puede leerse en el campo visual. Este intrincamiento es lo que Lacan intentó formalizar en el Seminario Los nombres del Padre:

\begin{abstract}
Ahora bien, esta cabeza de cordero con los cuernos enredados en una maraña de espinas que lo detiene, ese lugar de la maraña de espinas, quisiera comentárselos. El texto mismo hace sentir que se precipita sobre el lugar del sacrificio. ¿De qué viene ávidamente a reponerse cuando aquél cuyo nombre que es impronunciable lo designa, a él, para el sacrificio?
\end{abstract}

La respuesta está en lo que la pintura no da a ver. Caravaggio puso en escena la vibración de un movimiento; así es como encuentra lugar la remisión del shofar. El Seminario Los nombres del padre comenzaba entonces con lo que prometía saldar un aspecto oscuro del Seminario 10: el objeto voz. Sin embargo, la interrupción de la enseñanza, y el comienzo del Seminario 11, volvió a poner en situación la primacía del campo escópico, según explicaremos en el próximo apartado.

El Sacrificio de Isaac promueve la difícil figuración del objeto voz, el arduo aparecer del tiempo en el espacio visual (Cf. BAAS, 2012). Manifestar la latencia temporal y sonora de los objetos no ha sido una característica exclusiva de Caravaggio; en todo caso, lo que no debería sorprender es que este rasgo también forme parte de la producción de pintores modernos, como Cézanne: "El pintor retoma y convierte justamente en objeto visible lo que sin él permanece 
encerrado en la vida separada de su conciencia: la vibración de las apariencias, que es la cuna de las cosas.” (MERLEAU-PONTY, 1964, 53)

El objeto voz es la cuna desde la cual se abre el campo visual. Sin embargo, la vibración en el temblor invocante es sólo un aspecto del aparecer de los objetos, también es preciso prestar atención a lo que en ellos permanece invisible. Hacia este propósito corresponde encauzar el paso siguiente.

\title{
Los embajadores
}

"La mirada se ve", afirma Lacan (LACAN, 1964, 92). Para dar cuenta de esta presencia en el campo escópico, aunque escotomizada, Lacan desarrolla una lectura del fenómeno de la anamorfosis, al analizar el cuadro de H. Holbein Los embajadores. Esta pintura es comentada por Lacan como la fuente de la cual extraer un saber aplicable a toda obra de arte: la función cuadro.

\begin{abstract}
¿Cómo podríamos, en consecuencia, definir la "función cuadro"? Ponemos de relieve al menos dos significaciones. La primera está en referencia a la tyche, en el sentido en que la obra de arte debe tener, para ser considerada como tal, la capacidad de producir un encuentro con lo real. Pero este encuentro se funda sobre la inversión de la idea de aprehender la obra: no es el sujeto el que contempla la obra, sino es la exterioridad de la obra que aferra al sujeto. (RECALCATI, 2006, 22)
\end{abstract}

Ch. Buci-Glucksmann, en su libro Folie de voir. De l'estethique baroque (1986), presenta a la pintura de acuerdo con lo que entiende como una avidez de la mirada. Es importante destacar que Buci-Glucksmann apoya su exposición en argumentos tomados de Merleau-Ponty y Lacan. Lo esencial de la pintura se caracterizaría, entonces, por pretender ver lo invisible, en su afán por documentar el escorzo, el pliegue del movimiento y la perspectiva; y, respecto de este último punto, también, por ese fenómeno particular que es la anamorfosis. El término "anamorfosis" comenzó a utilizarse en el siglo XVII, aunque dicha técnica ya era tenida como un curioso corolario del descubrimiento de la perspectiva en los siglos XIV y XV. Lacan, por su parte, en la clase que venimos comentando, realiza una referencia a Baltrasäutis, recomendando su libro Ana- 
morfosis o perspectivas curiosas. Es importante constatar que Lacan ya había hecho alusión a este autor ejemplar en el seminario 7, siendo que en esta clase del 26 de febrero de 1964 afirma: "En mi seminario utilicé mucho la función de la anamorfosis, en la medida en que es una estructura ejemplar" (LACAN, 1964, 92). Acto seguido, pregunta a su auditorio: “¿en qué consiste una anamorfosis, simple, no cilíndrica?". Con estas dos últimas menciones queremos subrayar que Lacan no sólo se refiere de modo ocasional a esta estructura, sino que la considera ejemplar para el desarrollo de su seminario -y de su método, podría agregarse- y que había estudiado dicha estructura con detalle: las anamorfosis pueden ser planas o cilíndricas, según requieran un espejo cóncavo de reflexión, o no. Es notorio que Lacan está desarrollando su argumento teniendo en mente la articulación de la técnica artística. Sin embargo, el concepto específico del psicoanálisis del que busca dar cuenta en el recurso a esta técnica, se formula en la siguiente pregunta:

\begin{abstract}
¿Cómo es posible que, en ellas, a nadie se le haya ocurrido evocar $[\ldots]$ el efecto de una erección? [...] ¿Cómo no ver en esto, inmanente a la dimensión geometral dimensión parcial en el campo de la mirada, dimensión que nada tiene que ver con la visión como tal- algo simbólico de la función de la falta, de la aparición del espectro fálico? (LACAN, 1964, 95)
\end{abstract}

El análisis lacaniano de la mirada, luego de la introducción de la teoría del objeto $a$, busca dirimir una relación que había quedado pendiente a partir de la reformulación del falo simbólico en el seminario 8: la articulación entre falo y objeto. En el seminario 10, la propuesta encarnada del falo como órgano, haciendo de éste un objeto más en la serie de las formas del objeto $a$, más que pensar dicha relación disolvía el problema. Por un lado, Lacan realiza una lectura de la pintura a partir de sus elementos figurados, "esos objetos son todos símbolos de las ciencias y de las artes tal como estaban agrupadas en esa época en los trivium y quadrivium". En esta presentación falicizada de objetos, la aparición alegórica de la calavera no hace más que reenviar a la lección del seminario 8 respecto de la vacilación de la representación en la escena a partir de la manifestación de la presencia real. Sin embargo, esta no es toda la articulación que Lacan extrae en su lectura de Los embajadores: 
Todo esto nos hace ver que en el propio ámbito de la época en que se delinea el sujeto y en que se busca la óptica geometral, Holbein hace visible algo que es, sencillamente, el sujeto como anonadado -anonadado en una forma que, a decir verdad, es la encarnación ilustrada del menos fi de la castración. (LACAN, 1964, 95).

Se destaca, entonces, que en la articulación que Lacan promueve, la propuesta radica en articular el falo como símbolo con el objeto $a$ a través de la presencia negativa del falo imaginario: la captura de la mirada, en la cicatriz de la mancha, es la sutura que en lo imaginario encarna la operación simbólica del falo, que lleva a la mirada a condescender al placer de la visión. La operación del falo simbólico hace de la mirada una función pulsátil: "Pero la función de la mirada ha de ser buscada aún más allá. Veremos entonces dibujarse a partir de ella, no el símbolo fálico, el espectro anamórfico, sino la mirada como tal." (LACAN, 1964, 96)

La intersección del objeto $a$ mirada y el falo es sólo un aspecto de la estructura de la visión, en la cual el objeto opera como causa de deseo. Que el objeto $a$ tiene la estructura de un agujero, de una hiancia esplendente, es algo que sólo puede explicarse por su entrecruzamiento con el falo. Sin embargo, el objeto $a$ como mirada no sólo está polarizado hacia el deseo. En la clase del 4 de marzo de 1964, Lacan plantea la luz como un componente esencial de lo visible:

En el ámbito de lo geometral, como lo denominé, la luz parece, a primera vista, darnos el hilo conductor. En efecto, la vez pasada vieron cómo ese hilo nos une a cada punto del objeto, y lo vieron funcionar de verdad como hilo cuando atraviesa la retícula en forma de pantalla sobre la cual vamos a identificar la imagen. (LACAN, 1964, 100)

La imagen queda identificada, entonces, con una pantalla. No obstante, la función de la luz no debe ser confundida con la de la proyección geométrica. Para Lacan, la luz tiene una autonomía propia en el campo de la mirada: "La luz

5 En una respuesta a M. Safouan, respecto de si más allá de la apariencia está la falta o la mirada, Lacan afirma "El objeto a... vale como símbolo de la falta, es decir, del falo". Entendemos que en esta respuesta están articuladas las tres dimensiones: el objeto, el falo imaginario, el falo como símbolo. Por eso, en la misma respuesta Lacan puede escribir el falo simbólico con un menos adelante. 
se propaga en línea recta, sin duda, pero se refracta, se difunde, inunda, llena" (LACAN, 1964, 101). Lacan se propone demostrar que la relación del sujeto con la luz es distinta del lugar del punto geometral. La mirada de las cosas se estructura en el punto luminoso que captura la visión, tal como Lacan intenta demostrar con una anécdota personal en la que un pequeño pescador le indicó cómo era visto por una lata en el mar: "Lo que es luz me mira [...] En lo que se me presenta como espacio de la luz, la mirada siempre es algún juego de luz y de opacidad" (LACAN, 1964, 104). La mirada es esa reverberación ante la cual el sujeto se identifica como una mancha, pasando a formar parte del cuadro. Siempre estamos dentro del cuadro, recortados en una escena.

\section{¿Qué es un cuadro?}

La clase del 11 de marzo de 1964, titulada “¿Qué es un cuadro?” es el último eslabón de este recorrido, dando, a su vez, el punto de capitón a todos los desarrollos anteriores de la obra con la introducción de la noción de objeto $a$. De acuerdo con esta exposición, esta clase demuestra que el desarrollo de la teoría psicoanalítica lacaniana, a partir del seminario 8, culmina en una "teoría estética":

Uno de los juegos más fascinantes es encontrar en el cuadro la composición propiamente dicha, las líneas de separación de las superficies creadas por el pintor, las líneas de fuga, las líneas de fuerza. [...] En un cuadro, en efecto, siempre podemos notar una ausencia. (LACAN, 1964, 115).

Lugar de alojamiento de la mirada reverberante -piénsese en la Exposición de estampas de Escher-, en su análisis de la "función cuadro" Lacan recomienda una técnica de análisis visual que atienda al criterio composicional de la obra, a su forma y a su modo de aparición. Este último punto es ilustrado en la mención de un término que luego cobraría una relevancia excepcional en su obra: semblante.

El ser de la obra de arte es de semblante, y eso no quiere decir otra cosa que el hecho de que la obra se da a ver en un más allá de la apariencia, que, al mismo tiempo, es su aparecer. "El cuadro es esa apariencia que dice ser lo que da la apariencia" (LACAN, 1964, 119). La obra de arte no es ni tiene un ser por pro- 
curación, de ahí que el problema de la representación sea último gran problema que deba resolverse luego de la introducción de la noción de objeto $a$ :

El cuadro no actúa en el campo de la representación. [...] ¿O estará el principio de la creación artística en el hecho de que ésta extrae -recuerden como traduzco Vorstellungsrepräsentanz- ese algo que hace las veces de representación? ¿A eso les conduzco distinguiendo el cuadro de la representación? (LACAN, 1964, 115-117)

A la cuestión de la representación dedicaremos futuros trabajos, luego de haber desarrollado en estas páginas el modo en que la utilización de imágenes (en particular aquellas filiadas en la tradición barroca) tienen un valor metodológico en la enseñanza de Lacan.

Recebido em: 12.05.2016 Aprovado em: 30.07.2016

BAAS, B. Lacan, la voz, el tiempo, Buenos Aires, Letra Viva, 2012.

BUCI-GLUCKSMAN, Ch. La folie du voir: De l'esthétique baroque, Paris, Galilée, 1986.

HEIDEGGER, M. (1927) Ser y tiempo, México, FCE, 1989.

LACAN, J. (1960-61) El seminario 8: La transferencia, Buenos Aires, Paidós, 2004.

. (1961-62) El seminario 9: La identificación.

Inédito.

. (1964) El seminario 11: Los cuatro conceptos fundamentales del psicoanálisis. Buenos Aires, Paidós, 2007.

\section{Referência Bibliográfica}

- (1964-65). El seminario: libro 12. Problemas cruciales para el psicoanálisis. Inédito.

MILLER, J.-A. Comentario del seminario inexistente, Buenos Aires, Manantial, 1992.

A. La angustia lacaniana, Buenos Aires, Paidós, 2007.

RECALCATI, M. Las tres estéticas de Lacan, Buenos Aires, Del Cifrado, 2006. 